Journal of Clinical Investigation

Vol. 41, No. 8, 1962

\title{
URINARY 17-KETOSTEROID CONJUGATES IN HIRSUTISM
}

\author{
By PIERRE MAUVAIS-JARVIS AND ETIENNE-EMILE BAULIEU
}

(From the Laboratoire d'Endocrinologie, Chimie Médicale, Nouvelle Faculté de Médecine, Paris)

(Submitted for publication February 16, 1962; accepted April 5, 1962)

The principal urinary 17 -ketosteroids (17KS) were analyzed in 16 cases of hirsutism; their conjugated forms were separately cleaved, and the liberated $17 \mathrm{KS}$ were chromatographed and quantitated. Six were clinically classified as cases of Stein-Leventhal syndrome and the remaining 10 as "idiopathic hirsutism." ${ }^{1}$ The following conditions were excluded a priori: adrenal and ovarian tumors, Cushing's disease, and congenital adrenal hyperplasia.

Determination of total urinary $17 \mathrm{KS}$ in idiopathic hirsutism or in the Stein-Leventhal syndrome has not disclosed conclusive information regarding either the etiology or the pathologic physiology responsible for the appearance of hirsutism in these patients. On the other hand, fractionation of the urinary $17 \mathrm{KS}$ has revealed two types of urinary steroid abnormalities in hirsute patients. One abnormality is manifest primarily as an increase in urinary dehydroisoandrosterone ${ }^{2}$ both before and after administration of ACTH (2). The second abnormality is an increased urinary level of androsterone and etiocholanolone. In the latter instance some authors have suggested that the adrenal is responsible for the precursors of the increased androsterone and etiocholanolone (3-7), although others have suggested an ovarian origin and still others could not discern the glandular origin of these steroids $(8-10)$. A significant residual level of urinary $17 \mathrm{KS}$ after adrenal suppression following administration of

\footnotetext{
1 A preliminary report of these studies has been presented (1).

2 Dehydroisoandrosterone (D) : $3 \beta$-hydroxy-5-androsten-17-one. Androsterone (A) : $3 \alpha$-hydroxy-5 $\alpha$-androstane-17-one. Etiocholanolone (E) : $3 \alpha$-hydroxy-5 $\beta$-androstan-17-one. Isoandrosterone: $3 \beta$-hydroxy-5 $\alpha$-andros$\tan$-17-one. $3 \beta$-Etiocholanolone: $3 \beta$-hydroxy-5$\beta$-androstan-17-one. 11-Oxy-17-KS(11-O) : sum of $11 \beta$-hydroxyandrosterone, 11 $\beta$-hydroxyetiocholanolone, and 11-ketoetiocholanolone. Chorionic gonadotrophin (HCG). Sulfate ester (S). Glucuronoside (G) : $\beta(D)$-glucopyranosiduronate.
}

analogs of cortisol (11-15) favors an ovarian origin of the precursors responsible for the elevation of the androsterone and etiocholanolone values reported.

Since the highest blood concentrations of $17 \mathrm{KS}$ are represented by those steroids conjugated with sulfuric acid (16), we have restudied the urinary steroids in hirsutism, particularly in order to quantitate the sulfates of $17 \mathrm{KS}$ and to discern whether these values more truly reflect the metabolic alteration involved.

\section{METHODS}

Techniques of determination. In order to avoid spontaneous hydrolysis of the conjugated steroids, the 24hour urine collections were treated with $2 \mathrm{ml}$ of 1 per cent mercurithiosalicylic acid and $5 \mathrm{ml}$ of butanol. The urines were processed immediately or stored at $-10^{\circ} \mathrm{C}$ in the freezer until they could be analyzed.

Total 17KS was measured by the method of Jayle, Crépy and Scholler (17). Cleavage of the $17 \mathrm{KS}$ conjugates was carried out according to a previously published method (18) which completely separates the glucuronoside from the sulfate fractions by first utilizing the solvolysis technique of Burstein and Lieberman for the $17 \mathrm{KS}$ sulfates (19). The $17 \mathrm{KS}$ glucuronosides were extracted from ethyl acetate with $1 \mathrm{~N} \mathrm{NaOH}$ and were subsequently submitted to enzymatic hydrolysis with Helix Pomatia (L) $\beta$-glucuronidase (18). Liberated steroids were chromatographed on the ligroin-propanediol and the hexane: benzene $(1: 1)$-propanediol systems on a single sheet of paper. The $17 \mathrm{KS}$ were located and measured by the Zimmermann reaction. The variation of recovery was \pm 20 per cent. The chromatographic separation of dehydroisoandrosterone by this method was adequate, whereas androsterone and etiocholanolone traveled close to $3 \beta$-etiocholanolone and isoandrosterone, respectively. We have verified by adsorption chromatography and infrared spectrophotometry that these compounds do not account for more than 5 per cent of the total in the case of $3 \beta$-etiocholanolone, and 25 per cent in the case of isoandrosterone in normal and abnormal cases.

The 17-hydroxycorticosteroids were measured by the Porter-Silber method as modified by Scholler, Busigny and Jayle (20). 
URINARY CONJUGATED 17-KETOSTEROIDS IN HIRSUTISM

TABLE I

Urinary $17 \mathrm{KS}$ of seven normal females and five normal males *

\begin{tabular}{|c|c|c|c|c|c|c|c|c|c|}
\hline & \multirow[b]{2}{*}{ Age } & \multirow[b]{2}{*}{ Cycle } & \multirow{2}{*}{$\begin{array}{c}\text { Total } \\
17 \mathrm{KS}\end{array}$} & \multicolumn{3}{|c|}{ 17-Ketosteroid sulfates } & \multicolumn{3}{|c|}{ 17-Ketosteroid glucuronosides } \\
\hline & & & & D & $\mathbf{E}$ & $\mathbf{A}$ & $\mathbf{E}$ & A & 11-0 \\
\hline \multicolumn{10}{|c|}{ Females } \\
\hline $\begin{array}{l}1 \\
2 \\
3 \\
4 \\
5 \\
6 \\
7\end{array}$ & $\begin{array}{l}25 \\
30 \\
28 \\
20 \\
35 \\
27 \\
28\end{array}$ & $\begin{array}{l}\text { L } \\
\text { F } \\
\text { L } \\
\text { L } \\
\text { F } \\
\text { F } \\
\text { F } \\
\text { L }\end{array}$ & $\begin{array}{r}9.5 \\
8.2 \\
7.0 \\
\\
6.3 \\
9.3 \\
13.0\end{array}$ & $\begin{array}{l}0.20 \\
0.20 \\
0.15 \\
0.15 \\
0.20 \\
0.15 \\
0.40 \\
0.50\end{array}$ & $\begin{array}{l}0.50 \\
0.40 \\
0.35 \\
0.20 \\
0.10 \\
0.30 \\
0.40 \\
0.60\end{array}$ & $\begin{array}{l}0.50 \\
0.02 \\
0.05 \\
0.02 \\
0.10 \\
0.30 \\
0.07 \\
0.05\end{array}$ & $\begin{array}{l}1.5 \\
2.5 \\
2.0 \\
1.5 \\
2.0 \\
2.0 \\
2.5 \\
2.5\end{array}$ & $\begin{array}{l}1.2 \\
0.8 \\
0.3 \\
2.0 \\
1.0 \\
1.5 \\
0.8 \\
0.7\end{array}$ & $\begin{array}{l}1.5 \\
1.2 \\
1.0 \\
1.5 \\
1.0 \\
1.0 \\
1.7 \\
1.8\end{array}$ \\
\hline Mean & & & 8.8 & 0.24 & 0.36 & 0.14 & 2.1 & 1.0 & 1.3 \\
\hline Males & & & & & & & & & \\
\hline $\begin{array}{l}1 \\
2 \\
3 \\
4 \\
5\end{array}$ & $\begin{array}{l}29 \\
25 \\
20 \\
20 \\
29\end{array}$ & & $\begin{array}{r}10.5 \\
14.2 \\
9.7 \\
8.2 \\
9.1\end{array}$ & $\begin{array}{l}1.0 \\
1.0 \\
2.0 \\
0.8 \\
0.1\end{array}$ & $\begin{array}{l}0.3 \\
0.4 \\
0.3 \\
0.5 \\
0.1\end{array}$ & $\begin{array}{l}0.8 \\
0.5 \\
1.5 \\
0.8 \\
0.3\end{array}$ & $\begin{array}{l}2.0 \\
7.0 \\
1.5 \\
2.0 \\
2.0\end{array}$ & $\begin{array}{l}2.2 \\
2.0 \\
2.0 \\
2.0 \\
2.0\end{array}$ & $\begin{array}{l}2.5 \\
2.7 \\
2.6 \\
1.5 \\
1.7\end{array}$ \\
\hline Mean & & & 10.3 & 0.98 & 0.32 & 0.78 & 2.9 & 2.0 & 2.2 \\
\hline
\end{tabular}

* Mg per 24 hours, expressed as free steroids.

$\dagger$ Period of menstrual cycle: $F=$ follicular phase, $L=$ luteal phase.

Subjects. All subjects, except Patient 2 in Table II, were ambulatory.

The six cases of Stein-Leventhal syndrome were confirmed at laparotomy and by pathological examination of the removed ovarian wedges, as well as by resumption of ovulatory menses after wedge resection of the ovaries (1-6) (Table II); all of the patients with Stein-Leventhal syndrome presented some degree of hirsutism. Some of the patients classified as having "idiopathic hirsutism" (7-16) had menstrual abnormalities, but none of this group had enlarged ovaries. A 24-hour urine specimen served as a control in each patient studied.

Adrenal suppression was effected by the administration of dexamethasone, $1 \mathrm{mg}$ three times a day for 12 days. On days 6,7 , and 8 of adrenal suppression, 5,000 $\mathrm{U}$ of chorionic gonadotrophin 3 was administered intramuscularly each day. Urine was collected on day 12 of this regimen.

In addition to the regimen of adrenal suppression and ovarian stimulation, three patients (one with Stein-Leventhal syndrome and two with idiopathic hirsutism) were studied after the intravenous infusion of $25 \mathrm{mg} \mathrm{ACTH}$ administered over an 8-hour period.

\section{RESULTS}

\section{Normal individuals}

1) Control values (Table I; Figures 1 and 2). Studies of urinary $17 \mathrm{KS}$ of seven normal women are included in Table I. In this group there was

\footnotetext{
3 Endopancrine (Organon).
}

a noticeable preponderance of etiocholanolone over androsterone in the sulfate fraction (Figure 1). In the glucuronoside fraction, the etiocholanolone/ androsterone ratio was essentially the same.

Also listed in Table I are the analyses of urinary $17 \mathrm{KS}$ of five normal men. Among the dif-

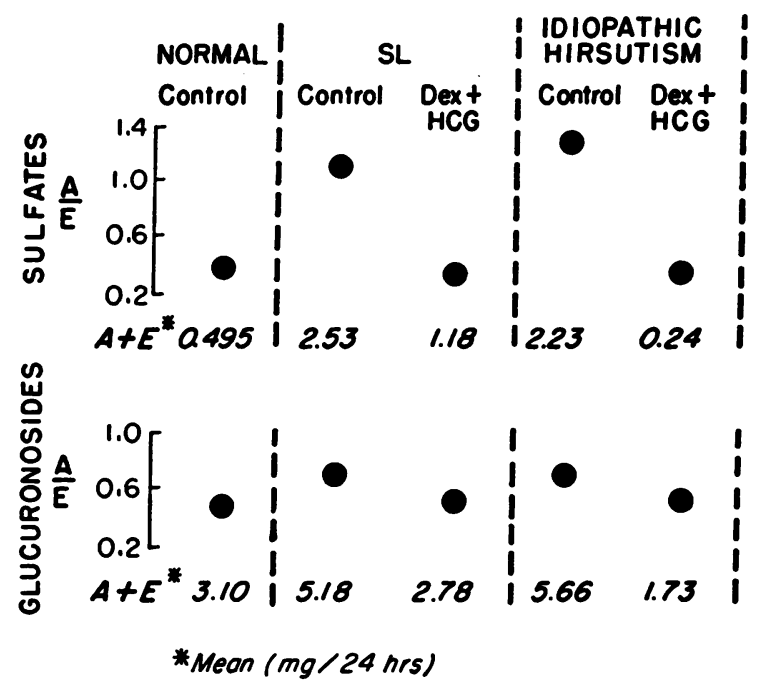

Fig. 1. URINARY ANDROSTERONE/ETIOCHOLANOLONE RATIOS (A/E) IN THE SULFATE AND GLUCURONOSIDE FRACrIons. The increase of $\mathrm{A} / \mathrm{E}$ in the sulfate fraction is obvious in the control urine of the patients. After dexamethasone and HCG, the increase of etiocholanolone sulfate decreases the value of $A / E$, 


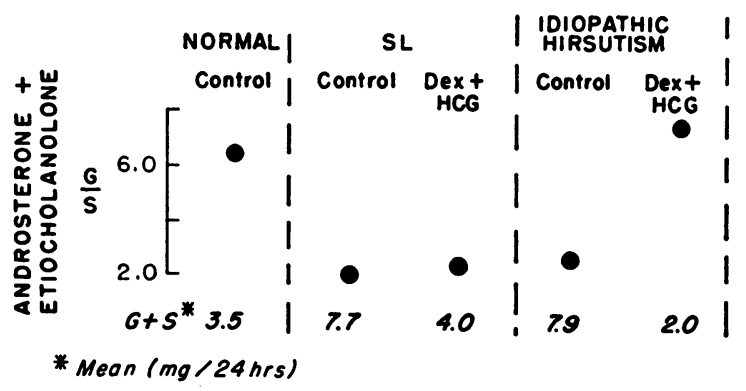

Fig. 2. Urinary androsterone and etiocholanoLONE GLUCURONIDE/SULFATE RATIOS (G/S). Increase of the sulfates in the control urine of the patients is evident from the decrease of $\mathrm{G} / \mathrm{S}$ ratios. The figures show the mean values of the sum of androsterone and etiocholanolone; they indicate a lack of correlation between G/S and $\mathrm{A}+\mathrm{E}$. ferences, we should like to call attention to the pattern of etiocholanolone and androsterone sulfates; unlike the women, every man had higher values of androsterone sulfate than of etiocholanolone sulfate. However, the etiocholanolone/androsterone ratio was still greater than 1 in the glucoronoside fraction.

In other words, the etiocholanolone/androsterone ratio is definitely lower in the urine of normal males than of normal females and, moreover, levels of androsterone sulfate are consistently higher in the urine of males than of females.

2) Adrenal suppression and ovarian stimulation. The normal women, after adrenal suppression and ovarian stimulation, had 17-hydroxy-

TABLE II

Urinary $17 K S$ in 16 patients with hirsutism *

\begin{tabular}{|c|c|c|c|c|c|c|c|c|c|}
\hline \multirow{2}{*}{$\begin{array}{l}\text { Patient } \\
\text { no. }\end{array}$} & \multirow[b]{2}{*}{ Age } & \multirow[b]{2}{*}{ Diagnosis } & \multirow{2}{*}{$\begin{array}{l}\text { Total } \\
17 \mathrm{KS}\end{array}$} & \multicolumn{3}{|c|}{$\begin{array}{l}\text { 17-Ketosteroid } \\
\text { sulfates }\end{array}$} & \multicolumn{3}{|c|}{$\begin{array}{l}\text { 17-Ketosteroid } \\
\text { glucuronosides }\end{array}$} \\
\hline & & & & $\bar{D}$ & $\mathbf{E}$ & $\overline{\mathbf{A}}$ & $\mathbf{E}$ & $\mathbf{A}$ & $11-0$ \\
\hline 1 & 24 & SL hirsutism $\dagger$ & 13.0 & 0.7 & 1.0 & 1.5 & 3.0 & 2.0 & 4.5 \\
\hline 2 & 18 & SL hirsutism $†$ & 14.0 & 2.0 & 2.5 & 2.0 & 3.0 & 2.0 & 3.0 \\
\hline 3 & 20 & SL hirsutism $\ddagger$ & 13.5 & 1.8 & 2.0 & 2.0 & 3.0 & 2.5 & 2.0 \\
\hline 4 & 25 & SL hirsutism $\ddagger$ & 7.5 & 1.5 & 0.8 & 0.9 & 2.7 & 2.1 & 1.5 \\
\hline 5 & 20 & SL hirsutism $\dagger$ & 11.6 & 0.9 & 0.6 & 0.9 & 2.6 & 2.1 & 1.5 \\
\hline 6 & 26 & SL hirsutism $\ddagger$ & 9.8 & 0.4 & 0.4 & 0.6 & 3.0 & 2.5 & 1.0 \\
\hline $7 \S$ & 25 & $\begin{array}{l}\text { Hirsutismł, primary } \\
\text { oligom., NO\| }\end{array}$ & 13.3 & 3.5 & 0.5 & 1.0 & 2.0 & 1.5 & 2.0 \\
\hline 8 & 22 & $\begin{array}{l}\text { Hirsutism } \dagger \text {, primary } \\
\text { oligom., NO }\end{array}$ & 19.0 & 4.0 & 2.0 & 3.0 & 4.0 & 3.0 & 3.0 \\
\hline 9 & 20 & $\begin{array}{l}\text { Hirsutism, } \dagger \text { acne, } \\
\text { normal cycles, NO }\end{array}$ & 12.8 & 0.5 & 0.8 & 1.0 & 2.0 & 1.5 & 3.0 \\
\hline 10 & 26 & $\begin{array}{l}\text { Hirsutism, } \dagger \text { acne, } \\
\text { secondary oligom., NO }\end{array}$ & 16.5 & 5.0 & 1.0 & 1.7 & 4.0 & 2.0 & 3.5 \\
\hline 11 & 18 & $\begin{array}{l}\text { Hirsutism, } \dagger \text { secondary } \\
\text { oligom., NO }\end{array}$ & 7.4 & 1.5 & 0.5 & 0.4 & 2.5 & 1.5 & 1.5 \\
\hline 12 & 15 & $\begin{array}{l}\text { Hirsutism, } \ddagger \text { primary } \\
\text { amenorrhea, NO }\end{array}$ & 16.0 & 0.3 & 0.5 & 0.8 & 5.0 & 4.0 & 4.5 \\
\hline 13 & 26 & $\begin{array}{l}\text { Hirsutism, } \ddagger \text { normal } \\
\text { cycles, NO }\end{array}$ & 15 & 5.0 & 1.0 & 1.5 & 3.0 & 2.0 & 1.5 \\
\hline 14 & 30 & $\begin{array}{l}\text { Hirsutism, } \dagger \text { normal } \\
\text { cycles, NO }\end{array}$ & 19 & 5.0 & 1.5 & 1.5 & 4.0 & 4.0 & 3.5 \\
\hline 15 & 22 & $\begin{array}{l}\text { Hirsutism, } † \text { normal } \\
\text { cycles, NO }\end{array}$ & 10.3 & 0.2 & 0.4 & 0.6 & 2.4 & 3.2 & 1.5 \\
\hline $16 \S$ & 18 & $\begin{array}{l}\text { Hirsutism, } \dagger \text { acne, } \\
\text { primary amenorrhea, NO }\end{array}$ & 15.0 & 0.8 & 1.8 & 0.8 & 3.0 & 2.0 & 2.8 \\
\hline
\end{tabular}

${ }^{*} \mathrm{Mg}$ per 24 hours, expressed as free steroids. $\mathrm{SL}=$ Stein-Leventhal syndrome; oligom. = oligomenorrhea; NO $=$ normal ovaries. See footnote ${ }^{2}$ for other abbreviations.

$\dagger$ Important hirsutism.

$\mp$ Moderate hirsutism.

Normal ovaries by physical examination.

i) Eonfirmed by laparotomy. 
corticosteroid levels of less than $1 \mathrm{mg}$ per 24 hours and total $17 \mathrm{KS}$ were consistently below $1.5 \mathrm{mg}$ per 24 hours. The small residue of $17 \mathrm{KS}$ was composed of glucuronosides of androsterone and etiocholanolone; the sulfate forms of these two steroids, as well as dehydroisoandrosterone sulfate and the 11-oxy-17KS glucuronosides, had virtually disappeared.

\section{Patients}

1) Control values (Tables II and III; Figures 1 and 2). The mean of the total $17 K S$ was higher in both groups of patients than in the normal women studied; the individual levels of androsterone, etiocholanolone, dehydroisoandrosterone, and the 11-oxy-17KS, when measured separately, were increased, but the degree of their elevation showed considerable variation.

When the 16 patients were considered as one group, the following observations were made. The 11-oxy-17KS were slightly elevated (150 to 200 per cent). The fractionation of 11 -oxy-17KS into $11 \beta$-hydroxyetiocholanolone, 11-ketoetiocholanolone, and $11 \beta$-hydroxyandrosterone did not add further information. The mean of the urinary dehydroisoandrosterone values was also increased $(p=0.01)$; however, the individual quantities showed tremendous variation, from normal to $+2,000$ per cent.

The most striking and consistent abnormality was found in the androsterone and etiocholanolone fractions. As glucuronosides, the androsterone was slightly more elevated (200 per cent) than the etiocholanolone (150 per cent). The sulfate fractions were more prominently elevated-androsterone 800 and etiocholanolone 300 per cent. The most impressive anomalies resided in the
TABLE III

Statistical study of data of Tables I and II

\begin{tabular}{|c|c|c|c|c|c|}
\hline & $*$ & S-A +S-E† & G-A + G-E & S-D & G-11-O \\
\hline $\begin{array}{l}\text { Normal } \\
\text { females } \\
\text { (8 determinations) }\end{array}$ & $\begin{array}{l}\mathbf{M} \\
\sigma \\
\sigma \mathbf{M}\end{array}$ & $\begin{array}{l}0.495 \\
0.235 \\
0.09\end{array}$ & $\begin{array}{l}3.10 \\
0.40 \\
0.15\end{array}$ & $\begin{array}{l}0.24 \\
0.21 \\
0.08\end{array}$ & $\begin{array}{l}1.34 \\
0.12 \\
0.31\end{array}$ \\
\hline $\begin{array}{l}\text { Stein-Leventhal } \\
\text { ( } 6 \text { cases) }\end{array}$ & $\begin{array}{l}\mathbf{M} \\
\sigma \\
\sigma \mathbf{M} \\
\mathbf{p}\end{array}$ & $\begin{array}{c}2.53 \\
1.30 \\
0.58 \\
<0.001\end{array}$ & $\begin{array}{c}5.18 \\
0.33 \\
0.15 \\
<0.001\end{array}$ & $\begin{aligned} & 1.22 \\
& 0.59 \\
& 0.26 \\
&= 0.001\end{aligned}$ & $\begin{aligned} & 2.25 \\
& 1.185 \\
& 0.48 \\
&= 0.05\end{aligned}$ \\
\hline $\begin{array}{l}\text { Hirsutism } \\
\text { (16 cases) }\end{array}$ & $\begin{array}{l}\mathbf{M} \\
\sigma \\
\sigma \mathbf{M} \\
\mathbf{p}\end{array}$ & $\begin{array}{c}2.34 \\
1.225 \\
0.32 \\
<0.001\end{array}$ & $\begin{array}{r}4.82 \\
2.80 \\
0.72 \\
=0.10\end{array}$ & $\begin{array}{r}2.07 \\
1.75 \\
0.45 \\
=0.01\end{array}$ & $\begin{aligned} & 2.52 \\
& 1.10 \\
& 0.285 \\
&=0.01\end{aligned}$ \\
\hline
\end{tabular}

* $M=$ mean mg per 24 hours; $\sigma_{M}=[\sigma / \sqrt{n}][\sqrt{n /(n-1)}]$.

+ See footnote ${ }^{2}$ for abbreviations.

increase in the sulfate fraction as a whole ( $p>$ $0.001)$ over the glucuronoside fraction $(p=0.1$; Table III) and in the increase of androsterone (primarily as sulfate) over etiocholanolone.

The results in the six Stein-Leventhal patients were similar, but not identical: the increase in dehydroisoandrosterone in these six patients was not so marked as in the group as a whole, but was consistently elevated, and the elevation was statistically significant $(p=0.001)$. Again, however, the most remarkable finding was the marked increase in the androsterone and etiocholanolone sulfates ( $>500$ per cent).

It is interesting to note the similarity between the urinary $17 \mathrm{KS}$ patterns of hirsute women and normal men.

2) $A C T H$ (Table IV). Similar urinary studies were carried out after the administration of ACTH to one patient with the Stein-Leventhal syndrome and to two patients with idiopathic hirsutism. In all three patients there was a significant increase in androsterone and etiocholano-

TABLE IV

Effect of ACTH administration upon urinary $17 K S$

\begin{tabular}{|c|c|c|c|c|c|c|c|c|c|}
\hline \multirow{2}{*}{$\begin{array}{c}\text { Patient } \\
\text { no.t }\end{array}$} & \multirow[b]{2}{*}{ Diagnosis } & \multirow[b]{2}{*}{ ACTH } & \multirow{2}{*}{$\begin{array}{c}\text { Total } \\
\text { 17 KS* }\end{array}$} & \multicolumn{3}{|c|}{ S-17KS* } & \multicolumn{3}{|c|}{ G-17KS* } \\
\hline & & & & D & $\mathbf{E}$ & A & $\mathbf{E}$ & $\mathbf{A}$ & $11-0$ \\
\hline 2 & Stein-Leventhal & 0 & 14 & 0.5 & 2.5 & 2.0 & 3.0 & 2.0 & 3.0 \\
\hline & & + & $\begin{array}{l}21 \\
10\end{array}$ & 1.0 & 2.5 & 2.5 & 6.0 & 5.0 & 7.5 \\
\hline 8 & "Idiopathic hirsutism" & $\mathbf{0}$ & 19 & 4.0 & $\begin{array}{l}2.0 \\
3.0\end{array}$ & 3.0 & 4.0 & 3.0 & 3.0 \\
\hline 16 & "Idiopathic hirsutism" & 0 & 15 & 0.8 & $\begin{array}{l}0.0 \\
1.8\end{array}$ & 0.8 & 3.0 & 2.0 & 2.8 \\
\hline & & + & 25 & 3.0 & 2.0 & 1.2 & 7.0 & 4.0 & 8.5 \\
\hline
\end{tabular}

* Mg per 24 hours, expressed as free steroids. See footnote ${ }^{2}$ for abbreviations.

† See Table II. 


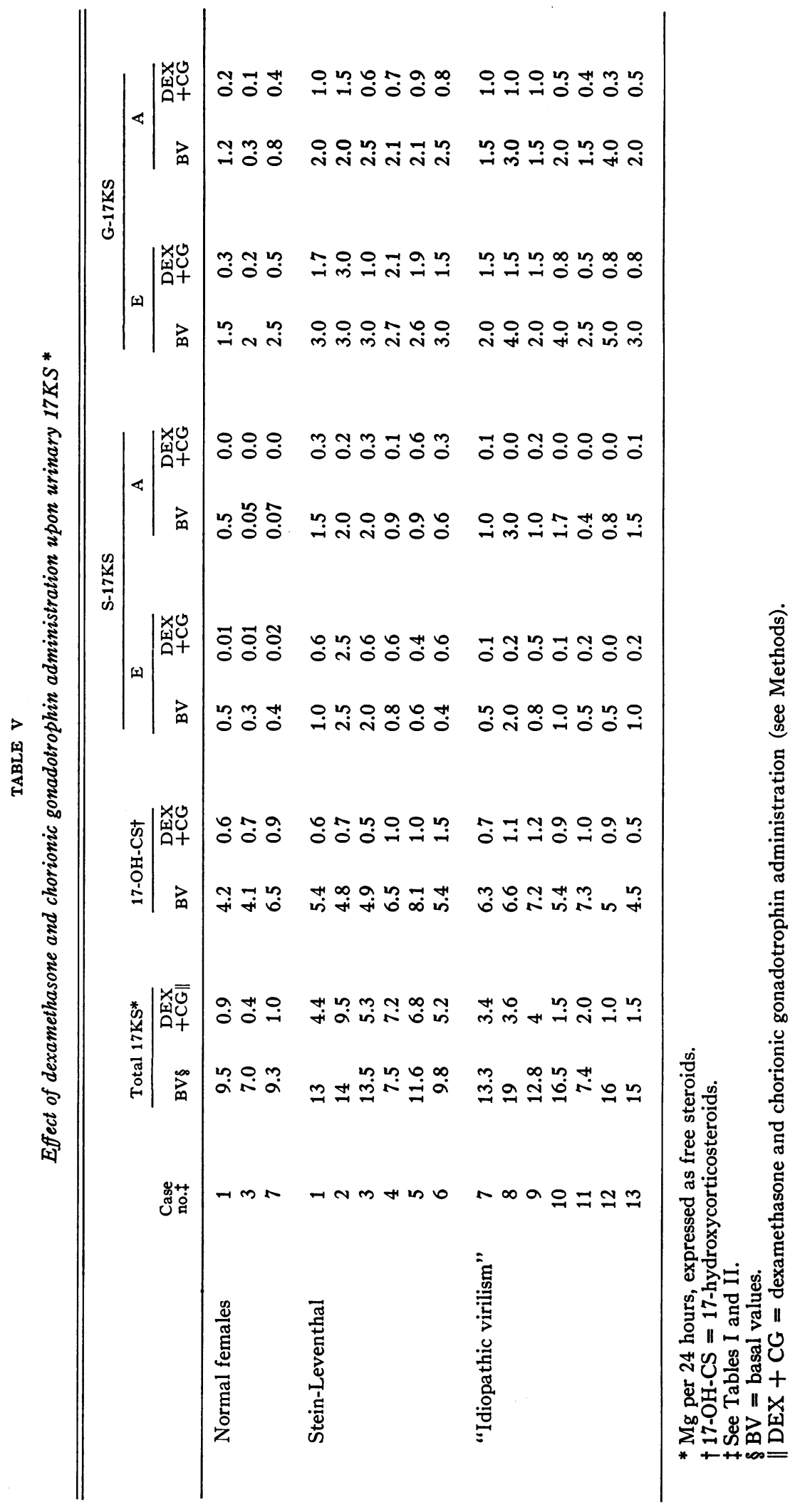


lone glucuronosides, as well as in dehydroisoandrosterone sulfate and the 11-oxy-17KS glucuronosides. On the other hand, androsterone and etiocholanolone sulfates remained virtually unchanged.

3) Adrenal suppression and ovarian stimulation (Table V; Figures 1 and 2). After combined adrenal suppression and ovarian stimulation, the six patients with Stein-Leventhal syndrome exhibited a significant level of androsterone and etiocholanolone which confirmed the previous findings of Jayle and colleagues (14). Both glucuronoside and sulfate forms of the steroids were present. In these experiments dehydroisoandrosterone (not included in Table V) was totally absent, as it was in the normal women examined under these conditions.

The seven cases of idiopathic hirsutism studied by this method, however, had virtually no urinary androsterone or etiocholanolone sulfate (except Patient 9) and may be distinguished from the cases of Stein-Leventhal syndrome by this criterion. At the same time, androsterone and etiocholanolone glucuronosides were present in significant (Patients 7-9) or markedly decreased amounts (Patients 10-13). Dehydroisoandrosterone was absent in this group also. The phenolsteroids, pregnanediol, and pregnanetriol determinations in Patients 7 and 8 may suggest "ovarian hyperthecosis" (14).

One further finding appeared in the patients with Stein-Leventhal syndrome. As shown in Table V and Figure 1, the androsterone/etiocholanolone glucuronosides ratio after dexamethasoneHCG administration was not altered, whereas the value for etiocholanolone sulfate was greater than that for androsterone sulfate in all except $\mathrm{Pa}$ tient 5. This finding appears more significant when one notes that, before the test, androsterone sulfate was as high or higher (except in Patient 2) than was etiocholanolone sulfate.

This preponderance of etiocholanolone is not easily explainable and the administration of dexamethasone as well as the pathological condition may be the cause.

To summarize the findings, after adrenal suppression by dexamethasone and ovarian stimulation by chorionic gonadotrophin in patients with hirsutism, there was significantly more androsterone and etiocholanolone than was present in the normal female under the same conditions. In idiopathic hirsutism the sulfate-17KS have completely disappeared. In the Stein-Leventhal syndrome, however, androsterone and etiocholanolone sulfates remained at a relatively high level, with the etiocholanolone sulfate value exceeding that of the androsterone sulfate.

\section{DISCUSSION}

A) Under experimental conditions employed for the independent measurement of the sulfate$17 \mathrm{KS}$ and glucuronoside-17KS (18), any free urinary $17 \mathrm{KS}$ would be measured as sulfates, but free $17 \mathrm{KS}$ are practically absent in human urine ( $<0.05 \mathrm{mg}$ per 24-hour urine); it is unlikely that the increased values of sulfate could be attributed here to $\beta$-glucuronidase present in the urine (21). First, the levels of sulfate-17KS observed were greater than could be expected from the hydrolysis of steroid glucuronosides by mammalian $\beta$-glucuronidase. Furthermore, the androsterone/etiocholanolone ratio was different in the sulfate fraction when compared with the androsterone/etiocholanolone ratio in the glucuronoside fraction. In addition, the increased urinary excretion of sulfoconjugated androsterone and etiocholanolone is indirectly confirmed by the increased blood levels of these compounds found in some of the patients and then isolated from plasma as the conjugates (22).

B) In patients exhibiting the Stein-Leventhal syndrome, the findings establish a definitive pattern of urinary steroid metabolites. All patients with Stein-Leventhal syndrome were subjected to laparotomy and each had a typically enlarged, pale, smooth-surfaced polycystic ovary characteristic of the disease. Concomitant with these pathological findings were elevations of androsterone and etiocholanolone sulfates in the control urine, with androsterone sulfate frequently being the preponderant fraction. In addition, there was persistent elevation of these sulfates to the extent of more than $0.7 \mathrm{mg}$ per 24 hours after adrenal suppression and HCG stimulation, but now with a shift to etiocholanolone sulfate dominance. These findings permitted a laboratory diagnosis prior to and substantiated by laparotomy.

In the cases of idiopathic hirsutism, an increase in androsterone sulfate and etiocholanolone 
sulfate was found during the control period which, as not with the Stein-Leventhal patients, virtually disappeared after dexamethasone-gonadotrophin treatment. This finding, combined with the difference in ovarian morphology, provided a point of distinction between patients with Stein-Leventhal syndrome and those with idiopathic hirsutism.

The persistence of more than $2 \mathrm{mg}$ of androsterone and etiocholanolone glucuronosides in Patients 7-9 after the combined treatment suggested an ovarian precursor(s) for these metabolites.

C) In certain patients, dehydroisoandrosterone was significantly elevated. The ovarian origin of dehydroisoandrosterone, in pathological conditions at least, has been suggested recently by isolation of dehydroisoandrosterone from ovarian tissue $(22,23)$, by experiments in vitro in which dehydroisoandrosterone was synthesized from acetate (24) or $\Delta^{5}$-pregnenolone (25), in metabolic studies in which the secretory rate of dehydroisoandrosterone was determined after adrenal suppression (26), and in studies of plasma dehydroisoandrosterone sulfate levels in SteinLeventhal syndrome (27).

In the cases reported here, however, urinary dehydroisoandrosterone was not detected after adrenal suppression and ovarian stimulation, and this is consistent with the assertion that dehydroisoandrosterone is only of adrenal origin. However, this assumption is based on a constancy of conversion of dehydroisoandrosterone to urinary sulfate of dehydroisoandrosterone, which may not be true (28).

D) In Stein-Leventhal syndrome as well as in idiopathic hirsutism, it is difficult to ascertain whether the etiology of hirsutism is of adrenal or ovarian origin. New findings favoring the ovarian origin of dehydroisoandrosterone have been cited above. In addition, it has recently been shown by techniques in vitro that the Stein-Leventhal ovaries may produce increased amounts of androstenedione, or testosterone, or both $(23,25$, 29-32). Recent work suggests that the secretion of small amounts of a potent androgen such as androstenedione or testosterone may induce significant virilization without concomitantly contributing to a significant increase in total urinary $17 \mathrm{KS}$ (33).
The results herein presented also favor the ovarian origin of a steroid that might cause hirsutism. During adrenal suppression, which was sufficient to decrease the 11-oxy-17KS and dehydroisoandrosterone of adrenal origin, the concomitant administration of HCG resulted in significant levels of androsterone and etiocholanolone in the urine in addition to increased levels of phenolic steroids under the same conditions (15). But this does not mean that ovarian steroid biosynthesis is the only abnormality in hirsutism. The slight, but significant elevation in 11-oxygenated $17 \mathrm{KS}$ also suggests an adrenal disorder.

E) Several explanations may be offered regarding the increased 17KS-sulfates. First, one may postulate the ovarian origin of an unknown precursor which would be metabolized to $17 \mathrm{KS}$ sulfates more than are the physiological hormone(s). A second explanation may be an altered metabolism of a known precursor. It is known that sulfoconjugation is relatively more important when the quantity of the substrate is increased (34). It does not seem likely that this mechanism applied in the experiments reported here, however, since it would not explain the failure of androsterone sulfate and etiocholanolone sulfate to increase after ACTH administration, whereas the androsterone glucuronoside and the etiocholanolone glucuronoside did show an increase. In addition, such a hypothesis would certainly not explain the relatively high levels of sulfates after adrenal suppression and ovarian stimulation, since then the total $17 \mathrm{KS}$ values are relatively low. Finally, as a third explanation, sulfoconjugation by the ovary may be considered, as has been previously suggested for dehydroisoandrosterone of adrenal origin (35).

F) The relationship between plasma and urinary levels of $17 \mathrm{KS}$-sulfates will be considered elsewhere (22). The existence of a cause and effect correlation between hirsutism and 17KSsulfates must, at the present time, be left to speculation. The apparent absence of hydrolysis in vivo of androsterone sulfate and etiocholanolone sulfate (36) leads us to assume that their urinary levels reflect their endogenous production.

\section{SUM MARY}

Six cases of Stein-Leventhal syndrome and ten cases of "idiopathic hirsutism" have been 
studied. The urinary 17-ketosteroids (17KS) have been separated as sulfoconjugated and glucuronoconjugated forms, and the free steroids derived from each conjugated group have been fractionated and measured after paper chromatography.

In the Stein-Leventhal syndrome, androsterone and etiocholanolone were significantly elevated, with androsterone showing the more marked elevation. In addition, the sulfate of androsterone and the sulfate of etiocholanolone were more increased than the corresponding glucuronosides.

Dehydroisoandrosterone (sulfoconjugated) was constantly and significantly elevated, whereas the 11-oxygenated 17KS (glucuronoconjugated) were only slightly increased.

After concomitant dexamethasone and chorionic gonadotrophin administration, dehydroisoandrosterone and 11-oxygenated $17 \mathrm{KS}$ were not detectable, but abnormally high levels of androsterone and etiocholanolone, especially of androsterone and etiocholanolone sulfates, persisted, with etiocholanolone sulfate predominating.

In idiopathic hirsutism, androsterone and etiocholanolone sulfates, particularly the former, were elevated, but disappeared after adrenal suppression and ovarian stimulation. After this test, androsterone and etiocholanolone glucuronosides were variable. In the untreated patients with idiopathic hirsutism, dehydroisoandrosterone and 11oxygenated $17 \mathrm{KS}$ were variable, and were not detectable after dexamethasone administration.

The usefulness of these findings as a diagnostic test and their implication in the pathogenesis of these conditions have been discussed.

\section{ACKNOWLEDGMENTS}

The authors wish to thank Dr. M. F. Jayle for his long-continued help. They are indebted to Dr. P. MacDonald (Columbia University, New York, N. Y.) for help in writing the manuscript.

\section{REFERENCES}

1. Mauvais-Jarvis, P., and Baulieu, E. E. Analyse et mode de conjugaison des 17-cétosteroïdes urinaires au cours des virilismes pilaires. Communication préliminaire. Ann. Endocr. (Paris) 1961, 22, 549.

2. Jayle, M. F., Malassis, D., and Pinaud, H. Excrétion de la déhydroépiandrostérone avant et après administration d'ACTH en pathologie surrénalienne. Acta endocr. 1959, 31, 1.
3. Kappas, A., Pearson, O. H., West, C. D., and Gallagher, T. F. A study of "idiopathic" hirsutism; a transitional adrenal abnormality. J. clin. Endocr. 1956, 16, 517.

4. Gallagher, T. F., Kappas, A., Hellman, L., Lipsett, M. B., Pearson, O. H., and West, C. D. Adrenocortical hyperfunction in idiopathic hirsutism and Stein-Leventhal syndrome. J. clin. Invest. 1958, 6, 783.

5. Perloff, W. H., Hadd, H. E., Channick, B. J., and Nodine, J. H. Hirsutism. A. M. A. Arch intern. Med. 1957, 100, 981.

6. Lipsett, M. B., and Riter, B. Urinary ketosteroids and pregnanetriol in hirsutism. J. clin. Endocr. 1960, 20, 180.

7. Brooks, R. V., and Prunty, F. T. G. Patterns of steroid excretion in three types of post-pubertal hirsutism. J. Endocr. 1960, 21, 263.

8. Gemzell, C. A., Tillinger, K. G., and Westman, A. A clinical study of ovarian pathology and the urinary excretion of 17 -ketosteroids. Acta endocr. 1959, 30, 387.

9. Pesonen, S., Timonen, S., and Mikkonen, R. Symptoms and etiology of the Stein-Leventhal syndrome. Acta endocr. 1959, 30, 405.

10. Lanthier, A. Urinary 17-ketosteroids in the syndrome of polycystic ovaries and hyperthecosis. J. clin. Endocr. 1960, 20, 1587.

11. Jailer, J. W., and VandeWiele, R. L. Studies in hirsutism. I. Urinary excretion of the neutral 17-ketosteroids. Gynaecologia (Basel) 1954, 138, 276.

12. Goldzieher, J. W., and Axelrod, L. R. Adrenal and ovarian steroidogenesis in the sclerocystic ovary syndrome (Abstract). Acta endocr. 1960, suppl. 51, p. 617.

13. Mahesh, V. B., and Greenblatt, R. B. Physiology and pathogenesis of the Stein-Leventhal syndrome. Nature (Lond.) 1961, 191, 888.

14. Jayle, M. F., Scholler, R., Mauvais-Jarvis, P., and Métay, S. Excrétion des stéroides chez des femmes présentant un virilisme pilaire associé à des troubles du cycle menstruel. Acta endocr. 1961, 36,375 .

15. Jayle, M. F., Scholler, R., Mauvais-Jarvis, P., and Szper, M. Exploration de la fonction ovarienne par les gonadotrophines chorioniques associées à la dexamethasone. Applications au diagnostic des virilismes ovariens. Clin. chim. Acta 1962. In press.

16. Baulieu, E. E. Three sulfate esters of 17 -ketosteroids in the plasma of normal subjects and after administration of ACTH. J. clin. Endocr. 1960, 20, 900.

17. Jayle, M. F., Crépy, O., and Scholler, R. Le dosage des 17-cétostéroides urinaires. Sem. Hôp. Paris 1957, 33, no. 4 (fiche technique).

18. Baulieu, E. E., Michaud, G., and Corpéchot, C. Méthode simple d'analyse chromatographique des 
17-cétostéroides urinaires destinée aux investigations cliniques. Ann. Biol. clin. 1961, 19, 291.

19. Burstein, S., and Lieberman, S. Hydrolysis of ketosteroid hydrogen sulfates by solvolysis procedures. J. biol. Chem. 1959, 233, 331.

20. Scholler, R., Busigny, M., and Jayle, M. F. Méthode de dosage des 17-21-dihydroxy-20-cétostéroides. Path. et Biol. 1957, 6, 49.

21. Hadd, H. E., Dorfman, R. I., Rhany, R. K., and Irwin, G. W. Response of urinary $\beta$-glucuronidase to testosterone in humans. Presented at the 1961 Meeting, Amer. Chem. Soc.

22. Baulieu, E. E., Mauvais-Jarvis, P., and Corpéchot, C. Submitted for publication.

23. Mahesh, V. B., and Greenblatt, R. B. Steroid synthesis in ovaries of normal and hirsute females. Endocrine Soc. Meeting 1961. Abstract 151.

24. Ryan, K. J., and Smith, O. W. Biogenesis of estrogens by the human ovary. IV. Formation of neutral steroid intermediates. J. biol. Chem. 1961, 236, 2207.

25. Axelrod, L. R., and Goldzieher, J. W. Steroidogenesis in the polycistic ovaries. Endocrine Soc. Meeting 1961. Abstract 44.

26. MacDonald, P. C., VandeWiele, R. L., and Lieberman, S. 1961. To be published.

27. Herrmann, W., Conrad, S. H., and Mahesh, V. Studies in hirsutism. Conjugated 17-ketosteroids in plasma. Endocrine Soc. Meeting 1961. Abstract 127.
28. MacDonald, P., VandeWiele, R. L., and Lieberman, S. 1961. To be published.

29. Lanthier, A., and Sandor, T. In vitro production of androgenic steroids by human normal and "Stein-Leventhal type" ovarian slices. Metabolism 1960, 9, 861.

30. O'Donnell, V. J., and McCaig, J. G. Biosynthesis of steroids by human ovaries (Abstract). Biochem. J. 1959, 71, 90.

31. Warren, J. C., and Salhanick, H. A. Steroid biosynthesis in the human ovary. J. clin. Endocr. 1961, 21, 1218.

32. Short, R. V., and London, D. R. Defective biosynthesis of ovarian steroids in the Stein-Leventhal syndrome. Brit. med. J. 1961, 1, 1724.

33. VandeWiele, R. L., and Lieberman, S. The metabolism of dehydroisoandrosterone in Biological Actvities of Steroids in Relation to Cancer, G. Pincus and E. P. Vollmer, Eds. New York, Academic Press, 1960, p. 93.

34. Schneider, J. J., and Lewbart, M. L. Fractionation and isolation of steroid conjugates. Recent Progr. Hormone Res. 1959, 15, 201.

35. Baulieu, E. E. Ester-sulfates de stéroïdes hormonaux. Isolement de l'ester-sulfate de 5 -androstène-3 $\beta$-ol 17-one (déhydroépiandrostérone) dans une tumeur cortico-surrénalienne. Absence de stéroïde libre. C. R. Acad. Sci. (Paris) 1960, 251, 1421.

36. Baulieu, E. E., and Michaud, G. Métabolisme des ester-sulfates d'androstérone et d'étiocholanolone. Bull. Soc. Chim. biol., Paris 1961, 43, 885. 